\title{
TRANSMEDIA: CONVERGENCIA SOCIAL Y PARTICIPATIVA
}

\section{TRANSMEDIA: SOCIAL AND PARTICIPATIVE CONVERGENCE}

\section{PABLO ESCANDÓN MONTENEGRO ${ }^{1}$}

Recibido : 15 de enero de 2017 Aceptado: 6 de marzo de 2017

\footnotetext{
${ }^{1}$ Director de Arsquitensis, transmedia cultural y patrimonial. Coordinador de Documentación en CIESPAL, Quito, Ecuador (pescandon@gmail.com; pablo@arsquitensis.net).
} 



\title{
TRANSMEDIA: CONVERGENCIA SOCIAL Y PARTICIPATIVA
}

\section{TRANSMEDIA: SOCIAL AND PARTICIPATIVE CONVERGENCE}

\author{
PABLOESCANDÓN MONTENEGRO
}

PALABRAS CLAVE: transmedia, cartografía, periodismo colaborativo, comunidades tecnológicas.

KEY WORDS: transmedia, cartography, collaborative journalism, technological communities.

\section{RESUMEN}

La narrativa transmedia es una propuesta que vincula a las comunidaforma de generar y consumir contenidos hiper y multimediales en entornos digitales, pero además implica la participación activa del usuario al momento de crear y consumir el texto, y se complementa con la forma diversificada de distribuirlo en distintas plataformas. Construir comunidades de conocimiento y de experiencias, es un fin no explícito de la narrativa transmedia. Por ello, desde el MedialabUIO, se hace una des tecnológicas y a los periodistas para que, de manera complementaria, coordinada y transmedial, presenten a la sociedad la utilidad de trabajar en equipos multi e interdisciplinares, con el aporte de sus conocimientos para una comprensión de la realidad más dinámica y cercana a los diferentes usuarios. Se toma el caso del voluntariado cartográfico en torno al terremoto del 16 de abril de 2016. 


\section{ABSTRACT}

Transmedia narrative is a way to generate and consume hyper and multimedia content in digital environments, but also involves the active participation of the user when creating and consuming the text, and is complemented by the diversified way of distributing it on different platforms. Building communities of knowledge and experience is an explicit purpose of the transmedia narrative. For this reason, since MedialabUIO, a proposal is made that links the technological communities and journalists so that, in a complementary, coordinated and transmedia manner, they present to society the usefulness of working in multi and interdisciplinary teams, with the contribution of their Knowledge for a more dynamic understanding of the reality and close to the different users. The case of volunteer cartography is taken around the earthquake of April 16, 2016.

\section{INTRODUCCIÓN}

El 16 de abril de 2016, a las 18h58, la costa norte de Ecuador sufrió un sismo de 7.8 grados en escala Richter, que fue sentido en la mayoría del territorio nacional. El efecto de esta catástrofe fue de magnitudes alarmantes y desde ese instante, la sociedad civil se organizó para dar socorro y apoyo a las labores humanitarias de rescate, desde sus conocimientos y experiencias. Es así que un grupo de expertos en el manejo de plataformas cartográficas digitales inició el levantamiento de datos y actualización de imágenes en línea con la finalidad de entregar a las distintas instancias gubernamentales de salvamento, información actualizada para poder tomar decisiones. En cuanto a los medios de comunicación, tanto analógicos como digitales, el uso de esta herramienta no es desconocida, pues en varios medios se generó la información como una actividad más de voluntariado, pero no integró su plataforma a la desarrollada por los voluntarios digitales, y de igual manera, los expertos cartógrafos no vincularon a los medios o el componente informativo en sus desarrollos.

Frente a esta miopía de ambos lados, desde el MedialabUIO se ha propuesto generar una plataforma de divulgación que comprende el uso de la 
cartografía para estos y muchos casos de desastres naturales, pero también de prevención en la población civil.

Proponemos que el contenido transmedia, en su generación debe vin- cular a las comunidades tecnológicas, de expertos, en este caso de cartografía y datos, con los periodistas, para generar contenidos útiles para todos los usuarios digitales.

\section{DESARROLLO LA CONVERGENCIA DIGITAL MEDIÁTICA}

En Internet existe una convergencia comunicativa de formatos y soportes que genera una nueva forma de comunicación, más directa, integral e integrada, que apela a los múltiples sentidos del usuario y que lo hacen partícipe en y de la construcción de mensajes.

Los entornos digitales son secuenciales, participativos, espaciales y enciclopédicos (Murray. 1999). De estos elementos, interesa destacar la participación de los usuarios, pues aquí radica la interactividad primera, no solo tecnológica de la programación, sino que es un entorno completamente dialógico y manipulable para establecer itinerarios de lectura y experiencia de uso, así como de aprendizaje.

Además, la capacidad y calidad enciclopédica de los entornos digitales permite construir una narrativa más rica que la que existe en los medios tradicionales, pues se puede abordar un tema desde múltiples e infinitos puntos de vista, entradas, formatos y recursos.
Todo espacio en la Red presenta estos elementos y la inmersión de la que habla Murray (1999) tiene que ver con la capacidad de crear una poética, con la finalidad de que el usuario participe en el espacio digital y lo haga suyo, lo asuma como una realidad más de su cotidianidad por medio de las pantallas móviles o estacionarias, que son las interfaces por medio de las cuales, el usuario ingresa a ese mundo virtual de realidad no contigua, sino simultánea.

La inmersión es una experiencia que se da mediante el desplazamiento a un no lugar (virtual) o ficticio completamente elaborado y programado.

La inmersión puede llevar consigo el que la mente se vaya inundando de sensación, el desbordamiento de estimulación sensorial que causaban los televisores de la novela de Bradbury, Farenheit 451. Mucha gente escucha música de esta manera, como si las partes verbales del cerebro se 
ahogasen placenteramente. Pero en un medio participativo, la inmersión implica aprender a nadar, a hacer las cosas que el nuevo entorno nos permite (Murray, 1999:111).

Murray dice que el computador es "un objeto encantado" (1999:111) para realizar actividades con contenido fantástico.

El encantamiento del ordenador nos proporciona un espacio público que se nos antoja al mismo tiempo muy privado e íntimo. En términos psicológicos, los ordenadores son objetos liminares, en el umbral entre la realidad exterior y nuestras propias mentes (Murray, 1999:112).

Al ingresar en la interfaz del computador, se realiza una reorganización simbólica del mundo, de la misma manera cuando se abre un periódico o un libro, pero el escenario reproduce de manera dimensional y multimedia esa realidad con varios formatos que imitan a la realidad sensible y física, en donde prima un medio, que depende del contenido; esto hace que el usuario ingrese a ese mundo, lo recorra y lo modifique de acuerdo con sus intereses.

¿Cómo sabremos qué hacer una vez dentro de la pantalla? ¿Cómo evitar que la ilusión se rompa? Hay que estructurar y controlar cuidadosamente la participación en un entorno de inmersión. Lo ideal es que el abanico de acciones posibles esté argumentalmente adaptado al mundo de la ficción... (Murray, 1999:119).

Murray habla de la estructura de ficción y tiene mucha razón, pues toda interfaz de los medios digitales es ficcional, ya que no existe en sí misma, no tiene lugar ni tiempo, por ello debe construir un andamiaje sólido para que el usuario se convenza que el espacio es real, en el soporte informático, y pueda desplazarse entre interfaces.

Carlos Scolari (2004) trata las interfaces y los entornos digitales interactivos como potenciales herramientas para captar usuarios, al integrar lo estructural con lo semántico de la interfaz, como mediadora con el usuario, y sus potencialidades creativas, de consumo y de diálogo.

La relación entre tecnología, cultura y sociedad que propone Scolari (2004) se fundamenta en que la interfaz es el espacio donde los flujos ideológicos se concretan, con las interacciones entre el diseñador y el usuario, confrontando sus lógicas de producción, pues las interfaces siempre generan desviaciones en la interpretación e imponen su propio ritmo donde se "libran batallas 
socioculturales y tecnológicas" (Scolari, 2004:234).

La interfaz se convierte en una herramienta estética de estructura y contenido, en donde esas batallas tienen que ver con los elementos de los entornos digitales que describe Murray: "sucesivos, participativos, espaciales y enciclopédicos" (1999:83), en donde hay intercambio, reinterpretación, lucha, traducción intercultural, "donde la lógica tecnoproductiva se negocia y modela a partir de los usos a que son sometidos los dispositivos de interacción" (Scolari, 2004:234).

Para Lev Manovich (2012), las interfaces son importantes, porque mediante ellas, el "software" se muestra al usuario para "crear, compartir, reusar, mezclar, gestionar y comunicar contenido" (27). "El software", para este autor, está enfocado al usuario y sus necesidades, por ello, las interfaces satisfacen esos requerimientos.

Las interfaces están en el ámbito de las hipermediaciones que Scolari (2008) trata, como una propuesta que indaga las nuevas configuraciones de los medios tradicionales y de los que surgen al margen y a la par de estos, pues se enfocan en las "dinámicas cognitivas y culturales que las tecnologías digitales han puesto en marcha(...)" (Scolari, 2008:114).

Las interfaces no solo están en la cibercultura sino en todos los artefactos tecnológicos, pero ahora mucho más en los ambientes digitales y las hipermediaciones se centran en los discursos que se dan en esos ambientes digitalizados (Scolari, 2008:115), pero no solo en la realidad virtual, sino en el diálogo y/o relación existente entre los movimientos sociales que se ven afectados o que usan estos entornos digitales para la comunicación.

(...) el término "interfaz de medio" (usado en la industria) es más preciso para describir cómo funcionan nuestras interfaces actualmente. Aquí podemos incluir interfaces de sistemas operativos, como Windows o Mac OS, Android o iOS; de consolas de videojuegos, teléfonos celulares, tiendas interactivas o instalaciones de museos, que emplean todo tipo de medios, además de los gráficos, para comunicar con los usuarios (Manovich, 2012:27).

David Bolter y Peter Grusin (2010) explican la lógica de la hipermediación mediante el uso de las interfaces en las pantallas de los computadores personales y en la Red y para ellos la hipermediación es un estilo visual fragmentado, indeterminado y heterogéneo que hace énfasis en el proceso de creación mucho más que en el producto realizado; no se limita exclusivamente a los desarrollos 
interactivos y multimedia, que son aleatorios, y promueven la constante práctica de la prueba y el error.

La hipermediación, al vincularse con la interfaz, tiene relación con todos los desarrollos visuales existentes; además se puede acceder a ellos por cualquier punto del relato creado: "Se trata de un medio que ofrece "acceso al azar", no tiene un comienzo físico, ni una mitad, ni un final" (Bolter y Grusin, 2010:9).

El deseo de inmediatez está expresado en la interfaz, y por ende, la hipermediación remite a la rapidez de la creación y difusión en entornos digitales, tanto en línea como fuera de ellos, debido al contexto mediático.

Una característica más de los medios digitales, de acuerdo con Bolter y Grusin (2012) es la remediación, que es "la representación de un medio en otro medio" (Ibídem, 17).

Los medios digitales hacen una remediación de los analógicos que los preceden con la finalidad de que el soporte sea transparente y el medio vernáculo se mimetice con y en la interfaz del computador. Por ello, en la remediación se halla una suerte de competencia o rivalidad entre los medios, segun el grado de presencia del uno en el otro.

La remediación es, también, una suerte de nueva lectura, adaptación o interpretación libre, en donde se puede tener la esencia del medio anterior, pero con las características del medio digital y donde las lógicas del nuevo se presentan como innovaciones o mejoras del anterior (Ibídem, 18)

Las hipermediaciones se complementan a las mediaciones propuestas por Martín Serrano y Martín-Barbero, en el ámbito de la cultura digital, en donde las interfaces de los espacios virtuales de comunicación y diálogo con los usuarios y comunidades sociales se ven afectadas, presentan estéticas y relatos inmersivos, fundamentados en los elementos descritos por Murray, pero que además, tienen su basamento en el hipertexto.

El hipertexto, como dice Alejandro Piscitelli (2002) es una "forma narrativa preprogramada indicativamente y donde las conexiones entre sentidos relevantes quedan en las manos de los lectores o usuarios -en vez de en las de los autores o programadores-" (Ibídem, 129).

El hipertexto genera relatos que rompen con la linealidad y la jerarquía autoritaria, por ello permite la participación, y desplaza a la palabra, como eje articulador de las sociedad letrada, a un plano de complemento, para que las otras narrativas lideren el mensaje para atender a los sentidos más inmediatos (Ibídem, 132).

Cada soporte tiene su forma de comunicación, por ello en la cibercultura, la forma de comunicar cambia, lo cual no quiere decir que el medio sea el men- 
saje sino que tiene usos, consumos y producciones distintas para comprender el contexto de la emisión y difusión de contenido en cierto soporte, como bien lo afirma Ramón Salaverría (2005) "así como la comunicación oral es siempre diferente de la escrita por su diferencia de canal, también es distinta la comunicación impresa de la mediada por ordenadores" (Ibídem, 21).

Manovich (2012) establece que el "software" cultural es el que crea contenidos "(es decir, los artefactos de los medios)" (Manovich, 2012:25), pero también este software incluye las herramientas, servicios y aplicaciones usados para la difusión, la comunicación y el intercambio del conocimiento, es decir, la Web social o los medios sociales. "En cierto modo, todo el "software" se volvió "software" social" (Manovich, 2012:25).

La tecnología digital ha mutado las formas de comunicación y de escritura, pues el ciberespacio entrega otros recursos y tiene reglas retóricas para generar y consumir contenidos que no son exclusivamente sonoros, visuales o gráfico-textuales, sino que son multimedia y de recuperación simultánea.

Para Manovich (2012) existen los medios híbridos, que incluyen lenguajes de los distintos medios existentes y que intercambian sus respectivas propiedades y retóricas para crear nuevas estructuras narrativas, propias del medio híbrido, aquí radica la diferencia con los multimedia.

Los medios híbridos se distinguen de los multimedia porque "la estructura original de los datos es afectada" (Manovich, 2012:147), es decir, se crea una propia estructura informática de la narrativa, no es simplemente una sucesión ni una yuxtaposición de elementos provenientes de diversos medios. Es la creación de una nueva interfaz, codificada con un lenguaje diferente en un soporte nuevo. Es la transformación de los videos, las Web y los gráficos, en su estructura y visualización.

Lev Manovich (2012) establece que la cultura digital está caracterizada por el desarrollo del "software" al que denomina cultural, muy relacionado con la Web 2.0, que permite crear, editar y rehacer un mismo documento. La comunicación digital está mediada por el "software" que interviene en actividades culturales y que, incluso, es parte de la cultura.

La interactividad de la que habla Manovich (2012:24) está enmarcada en la categoría del "software" de aplicaciones, que permite la edición y corrección en línea de un documento, pero además basado en la sincronía.

Esta interactividad permite que los usuarios realicen una inmersión con y una vinculación mayor con el espacio virtual en el que están creando o siendo 
partícipes de una generación colaborativa de contenido. "Quizá el usuario no siempre pueda crear contenido, pero sí puede navegarlo e interactuar con él" (Manovich, 2012:24).

Una forma básica de interactuar y participar inmersivamente es el diálogo y la conversación, elementos indispensables en la comunicación digital. La interactividad no es otra cosa que conversar con el modelo de trayecto propuesto por el diseñador del entorno virtual multimedia.

Manovich fundamenta su análisis de los nuevos medios (2006) en la base de la plataforma: el lenguaje binario, la forma de representar gráfica y espacialmente los módulos, la actualización, la forma cómo se puede variar y adaptar. El "software" cultural de administración Web cumple con todos estos elementos.

1. Los nuevos medios son medios analógicos convertidos a una representación digital. A diferencia de los medios analógicos, que son continuos, los medios codificados digitalmente son discretos.

2. Todos los soportes digitales (los textos, las imágenes fijas, la información del tiempo en vídeo o audio, las formas y los espacios tridimensionales) comparten el mismo código digital, lo cual permite que distintos tipos de soportes se presenten por medio de una sola máquina, el ordenador, que actúa como un dispositivo de presentación multimedia.

3. Los nuevos medios permiten el acceso aleatorio. A diferencia de la película o de la cinta de vídeo, que guarda los datos de manera secuencial, los mecanismos de almacenamiento informático permiten acceder a cualquier elemento a la misma velocidad.

4. La digitalización comporta inevitablemente una pérdida de información. A diferencia de la representación analógica, una representación digitalmente codificada contiene una cantidad fija de información.

5. A diferencia de los viejos medios, en los que cada copia sucesiva sufría una pérdida de calidad, los medios codificados digitalmente se pueden copiar de manera ilimitada sin degradación.

6. Los nuevos medios son interactivos. A diferencia de los viejos medios, donde el orden de presentación viene fijado, ahora el usuario puede interactuar con el objeto mediático. En ese proceso de interacción puede elegir qué elementos se muestran o qué rutas seguir, generando así una obra única. En este sentido, el usuario se vuelve coautor de la obra (Manovich, 2006:20-21). 


\section{NARRATIVA TRANSMEDIÁTICA}

Denis Porto y Jesús Flores (2012) abordan el tema de la poshipertextualidad y la transmediación como elementos característicos de la comunicación digital aplicada y complementaria a los medios sociales.

Henry Jenkins, en su blog (2014) hace una redefinición de lo que es la narración transmedia, a partir de la primera acepción que plasmó en Convergence Culture (2009):

La narración transmediática representa un proceso en el que los elementos integrales de una obra de ficción se esparcen sistemáticamente a través de muchos canales de distribución con el propósito de crear una experiencia de entretenimiento unificada y coordinada. Lo ideal es que cada medio proporcione su propia contribución original al desarrollo de la historia (Jenkins, 2014).

Y precisa un poco más, pues la narrativa transmedia es una lógica narrativa que organiza un flujo de contenido mediante diferentes medios y soportes, por lo tanto, se puede pensar en "marca transmediática, representación transmediática, ritual transmediático, juego transmediático, activismo transmediático, y espectáculo transmediático, como otro tipo de lógicas disponibles" (Jenkins, 2014).

Por lo tanto, no se aplica exclusivamente a las obras de ficción, sino a todas las obras (contenidos) que manejan información y generan narrativas, es decir, relatos que reflejan la ideología (Martín Serrano, 2008) de una institución.

Para algunos escritores, la narrativa transmedia se limita exclusivamente a la reducción de múltiples plataformas mediáticas sin profundizar en las relaciones lógicas entre esas extensiones mediáticas. Lo más importante para Jenkins (2014) es la relación entre medios y no la contabilidad del número de plataformas utilizadas; esta relación se basa en la serialidad.

(...)La serialidad implicaría el desarrollo de una historia a través del tiempo, normalmente a través de un proceso de despedazamiento (crear pedazos significativos de la historia) y dispersión (dividir la historia en entregas interconectadas). Un concepto central de este proceso es la creación de una historia con gancho o cliffhanger que motive al consumidor a volver para conocer más de la misma historia. Históricamente, la serialidad ocurre dentro del mismo texto (Jenkins, 2014). 
Vicente Gosciola (Porto y Flores, 2012) establece las características de la narrativa transmedia, las cuales concuerdan con lo propuesto por Jenkins:

- es un formato de estructura narrativa;

- es una gran historia compartida en fragmentos;

- $\quad$ sus fragmentos son distribuidos entre múltiples plataformas de media;

- circula por las redes sociales;

- apoya esta distribución en la estrategia denominada "viral" o "spreadable";

- adopta como herramienta de producción dispositivos móviles, como teléfonos celulares (móviles) y tablets (Porto y Flores, 2012:64).

Ambos textos asumen lo fundamental: la creación de un mundo narrativo, fragmentado y entregado a los usuarios o receptores de manera seriada mediante diversidad de plataformas, principalmente difundido por las redes sociales, enfocado al consumo en dispositivos móviles.

José Ignacio Galán (2014) establece, a partir de Convergence Culture (Jenkins, 2009) los elementos de la transmedialidad, en donde los usuarios, no solo son consumidores de contenidos, sino que desde una asunción de fanáticos (fan) abordan el texto o la obra narra- da desde sus interpretaciones, sensibilidades, afectos y proyecciones, dentro de un continuo crear en la obra.

1.- Expansión y profundidad (spreadability versus. drillability).

2.- Continuidad y multiplicidad (continuity versus. multiplicity).

3. Inmersión y extracción (immersion versus. extractability).

4. Construcción de mundos (worldbuilding).

5. Serialidad (seriality).

6. Subjetividad (subjectivity).

7. Ejecución (performance).

Estos son los principios que Jenkins (2009) establece para la narrativa transmedia, pero además, existen estrategias para que estos principios sean más efectivos entre los usuarios-fans y los neófitos, como el propio Galán enumera:

Gamificación (Juguetización), que es el uso de la mecánica del juego en contextos ajenos a los propios juegos, con el fin de que las personas adopten cierto comportamiento de participación, generación de contenidos, inmersión en la historia (Galán, 2014).

Experiencia personalizada, mediante la cual los propios usuarios-fans son los generadores de contenido, a partir de sus sensibilidades, experiencias, intereses (son prosumidores) y sus espa- 
cios en los medios sociales proponen contenidos importantes para el relato principal (Galán, 2014).

Storytelling (arte de contar historias), mediante lo cual se potencian y se privilegian las historias, no tanto los conceptos. "El ser humano siempre se ha contado el mundo para, después, reproducirlo. La apropiación no provenía solo de la razón, de la idea transmitida, sino de las emociones, de las relaciones que se establecían con el relato, de la identificación emocional con lo narrado" (Galán, 2014).

Glocalización, que hace referencia a lo global (interconectado mundialmente), y a lo local (lo cercano y próximo).

Multiplataforma y multiformato, basado en la convergencia de medios, a través de las distintas plataformas: Internet, móvil, redes sociales, lo real, etcétera; cada plataforma aporta, con sus características propias y diferentes a las de las otras, al relato (Galán, 2014).

Aspectos técnicos, pues los guionistas o creadores de narrativas transmedia deben conocer, no manejar a la perfección la geolocalización; los juegos multiplataforma interactivos, online y offline; la realidad aumentada; la proyección de imágenes virtuales sobre objetos reales mediante dispositivos como el celular; la creación de mapas; y la visualización de datos (Galán, 2014).

Es así que como dice Scolari (Porto y Flores, 2012:64), la narrativa transmedia tiene "como propuesta la reconstrucción cognitiva a partir de múltiples plataformas".

\section{PERIODISMO TRANSMEDIA}

De acuerdo con Jenkins (2007), la narración transmediática consiste en la diseminación de contenidos en muchos canales con la finalidad de generar entretenimiento unificado y coordinado, lo que hace que la industria cultural se consolide y cree sinergias entre plataformas.

Lo transmediático, en su inicio, tiene que ver con la ficción de héroes y superhéroes, o personajes de caricatura, que nacen de series de TV, de cómics, de películas, por lo cual, su característica de serialidad, participación, multicontenido y explotación de tramas y subtramas es una característica de estos fenómenos de la industria cultural, y su presencia se extiende a todos los formatos: radio, tv, digital, impreso, "marketing"...

En este sentido, Anahí Lovato (2015) está de acuerdo con Henry Jenkins (2006) cuando propone que lo importante de la convergencia mediá- 
tica no reside en lo tecnológico sino en asumir una nueva forma cultural de producción y consumo de contenidos, mediante la cual se promueve a los consumidores y productores de información que generen sinergias entre ellos. Allí radica la inteligencia colectiva, en su participación, no en el canal.

"La convergencia mediática altera la relación entre las tecnologías existentes, los mercados, los géneros y el público. Es un proceso, no un punto final. Implica un cambio tanto en el modo de producción como de consumo de medios." (Lovato. 2015)

Es entonces, que el transmedia es una forma de crear lógicas narrativas, no plataformas, únicamente. Por ello, en su uso periodístico, tiene que ver con las formas de contar y de integrar a los testigos-participantes en la historia, mediante el uso de herramientas tecnológicas, pero en relatos profundos, tanto en construcción como en consumo e investigación.

En Periodismo Transmedia: miradas múltiples, (Renó, Campalans, Ruiz y Gosciola. 2013) existen diferentes abordajes al tema de la narrativa transmedia.

Joao Canavilhas (en Renó, D., Campalans, C., Ruiz, S., Gosciola V. 2013) afirma que la narrativa transmedia no es aplicable a todos los géneros periodís- ticos, pues los datos de la información rápida e inmediata y sus textos, como la noticia, por ejemplo, no es campo fértil para el transmedia, debido a su carácter temporal de instantaneidad. (64)

El transmedia, dice Canavilhas (2013), es más adaptable a géneros propios de la Web como el "newsgame" o las infografías interactivas multimedia, así como el gran reportaje o especial multimedia, ya que se trata de "un género a profundidad que se diferencia de las noticias por la obligatoriedad de incluir contextualización diacrónica y sincrónica, por permitir una mayor libertad narrativa y por no ser tan perecible como una noticia, lo que le permite tener un ciclo de vida más duradero". (65)

De esta manera, este formato de la industria cultural y convergencia digital no es para todo el periodismo digital, pues su profundidad, contextualización y estética no es instantánea, sino un proceso dilatado de construcción de un mundo narrativo en la Red.

Thom Gencarelli (en Renó, D., Campalans, C., Ruiz, S., Gosciola V. 2013) hace una síntesis, en cuatro puntos, de la perspectiva transmediática en el periodismo, inserto en la industria cultural.

El autor asegura que la narrativa transmedia posiciona a la audiencia de manera activa y no es simplemente consumidora de platos elaborados por la industria cultural, ya que la gente le da 
nuevos significados al crear, continuar y enriquecer el valor de las historias. Por lo tanto, los medios de masas ya no son los dominantes en este tipo de narrativas, pues los consumidores aportan con sus conocimientos, sensibilidades y puntos de vista, al ser quienes definen itinerarios de lectura y de producción de contenidos, de esta manera se sale del circuito mercantil establecido por los medios industriales. Además, los usuarios son testigos principales de lo que ocurre con la historia y de esta manera son capaces de anular lo que los medios masivos imponen, en agenda y en forma de consumo; lo que genera una nueva era de contenido generado por el usuario. (80)

Desde esta perspectiva, hay que conocer la industria cultural para poder modificarla y no caer en sus lógicas mercantilistas de consumo, pero desde este conocimiento es importante la estética de resistencia, es decir, una estética desde los diferentes tipos de usuarios que tienen los medios digitales en América. Desde estas particularidades se deben generar las estéticas narrativas, para que estas no se conviertan en espacios clonados de CCN, MSNBC o de los GDA.

Said-Hung, Römer y Valencia-Cobos (en Renó, D., Campalans, C., Ruiz, S., Gosciola V. 2013) también notan que generar contenido para las plataformas y narrativas transmedia es uno de los retos actuales, en el que inciden la formación, pago, horas y condiciones de trabajo de los periodistas en los medios y la adaptación de las herramientas digitales para cada medio y sus usuarios-periodistas, quienes deben ser capaces de añadir capas de interactividad en las diferentes tramas y subtramas que son narradas en una noticia o contenido periodístico, con la capacidad de entregar más libertad de navegación a los usuarios-lectores, para todos los tipos de pantallas. (102)

A partir del estudio de cibermedios iberoamericanos, los investigadores concluyen en:

1) la necesidad que tiene el periodismo transmedia de contar con una estructura de acción efectiva de este modelo desde los medios digitales existentes; 2) la necesidad de actividades de formación a nivel profesional en el periodismo que se ejerce en estos medios digitales para poder llevar a la realidad buena parte de los factores que se logran distinguir como parte del modelo de periodismo transmediático; 3) revisar y poner en marcha acciones que ayuden al uso activo e intensivo de las herramientas y recursos de interacción en el interior de los medios digitales y 4) favorecer procesos y escenarios para el aumento de la universalización del servicio de internet en la mayoría de los países analizados, lo que incidi- 
ría en la generación de un contexto más favorable en el desarrollo de los medios digitales, y con ellos del periodismo transmedia en los países iberoamericanos. (113)

Es así que una de las salidas pertinentes para el transmedia no es solo desde los medios sino, fundamentalmente desde la formación de periodistas, tanto de universidades como de centros de formación, en donde hay que profundizar en temas de narrativas, de estéticas y de plataformas para contar historias con contexto, con tiempo de navegación, con tiempo de creación.

Pero esta formación tiene que ver con inversión, a la que le huyen todos, pues el efecto de instantaneidad de la Red está sobre el efecto de crear comunidad y poner los conocimientos en común, como lo proponen Carlos Arcila y Mabel Calderón Said-Hung, Römer y Valencia-Cobos (en Renó, D., Campalans, C., Ruiz, S., Gosciola V. 2013), al hacer un estudio sobre el transmedia en espacios dedicados a la difusión de ciencia y tecnología:

Lo transmedia en la investigación se hace evidente en las prácticas transdisciplinarias: trabajan articuladamente diferentes disciplinas a través de diferentes medios para conocer un objeto de estudio. Esto supone un trabajo colaborativo intenso y el flujo de muchos tipos de mensajes por diferentes canales para poder construir un relato coherente. Por ello la apertura del mensaje es de particular importancia: el criterio de los científicos y las voces de los seguidores entusiastas de la ciencia y de las comunicaciones, haciéndose preguntas sobre los resultados, se pueden hacer presentes en los múltiples relatos resultantes tanto de la actividad científica como de la actividad periodística. (72)

Luciana y Dennis Renó (2013) abordan el tema de uso de mapas interactivos en la utilización de información periodística, y dicen que el trabajo cartográfico es utilizado "como representación de un territorio de forma simplificada, es decir más sencilla de comprender, con una función informativa."

Los datos se dividen en capas: demográficas, físicas, de producción, vial, etcétera; con información que puede y es utilizada en y por otras plataformas "para que la información que se desea pasar sea más completa" (Renó. 2013).

Entre las conclusiones de este texto, se considera que los medios deben salir de la endogamia del oficio; ahora se necesitan equipos multi e interdisciplinares desde varios oficios y profesiones. En una redacción digital 
deben estar incorporados "ingenieros de computación capaces de pensar en algoritmos y de manosear software para la construcción de contenidos interactivos. Entre ellos están los mapas interacti- vos, que proporcionan a los ciudadanos contemporáneos la participación a partir de navegación y de retroalimentación" (Renó. 2013).

\section{PARTICIPACIÓN COLABORATIVA Y CREACIÓN DE COMUNIDAD}

De acuerdo con Doheney-Farina (en Jones 2003:23), una comunidad existe cuando se establece un vínculo entre el espacio y las necesidades que se generan en torno a este, por lo tanto tiene que ser vivida.

Se parte de esta definición para confirmar que la comunidad creada en torno a la etiqueta \#MappingEcuador es una comunidad que se originó para dar solución a una necesidad: generar conocimiento y utilidad en torno a la cartografía digital y los sistemas de información geográficas, mediante la transformación y actualización de Open Street Map, por lo tanto "la construcción social de la realidad que existe en Internet no está constituida por las redes que utilizan los usuarios de $\mathrm{CMO}$, está constituida en las redes" (Jones. 2003: 25).

Desde el LlactaLab, un espacio de investigación liderado por Daniel Orellana (@temporalista) de la Universidad de Cuenca, se inició el contacto con activistas de todo el mundo, para trabajar en la actualización de Open Street Maps.

Según reportes del propio Orellana, al 2 de mayo de 2016 existen 2.301 contribuciones desde Nepal, Alemania, Francia, Colombia, Estados Unidos, España y Ecuador, que actualizaron y/o generaron información de 2’918.368 elementos.

Además se realizaron varios mapathones, jornadas de capacitación en el uso de Open Street Maps para voluntarios que deseaban y desean colaborar con el trabajo. 


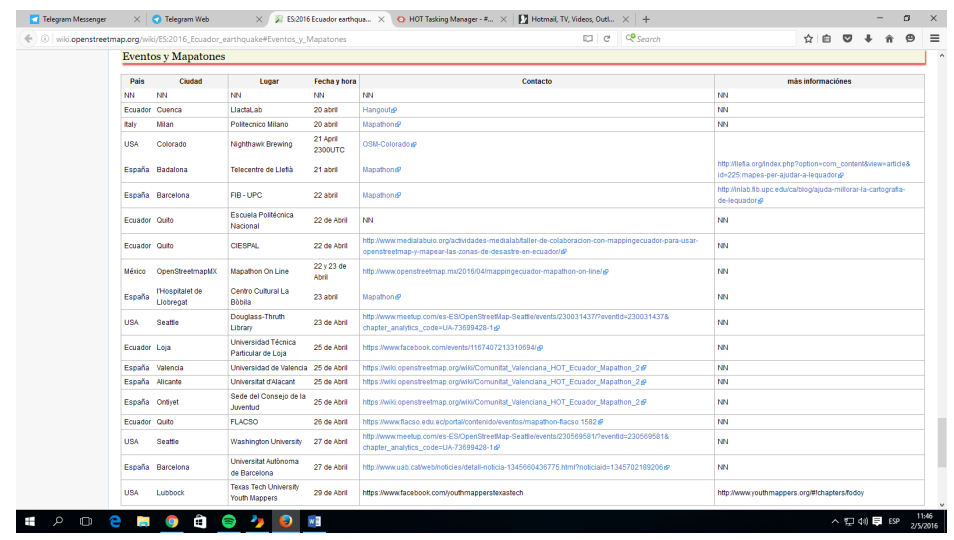

Imagen 1: Tabla de mapatones realizados e ingresados en la wiki de openstreetmap.

De esta manera se ratifica lo tecnología, se la implementa y se usa; en que Jones (2003. 34) cita de Gellespie este sentido la plataforma que usa esta y Robins acerca de que las nuevas tec- comunidad privilegia los recursos diginologías de la comunicación impactan no solo en los procesos y relaciones sociales, además de los lugares, sino que tales de código abierto, como principio ideológico y vivencial para poder crear y modificar la propia plataforma.

también lo hacen en cómo se diseña la 


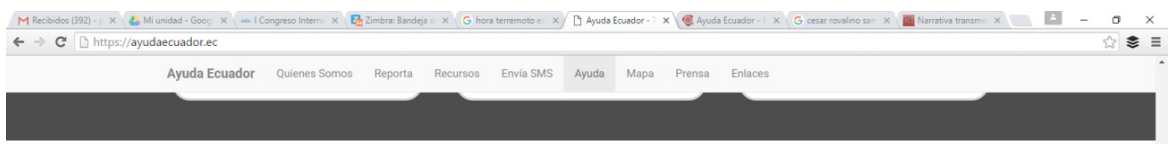

Mapa de Reportes
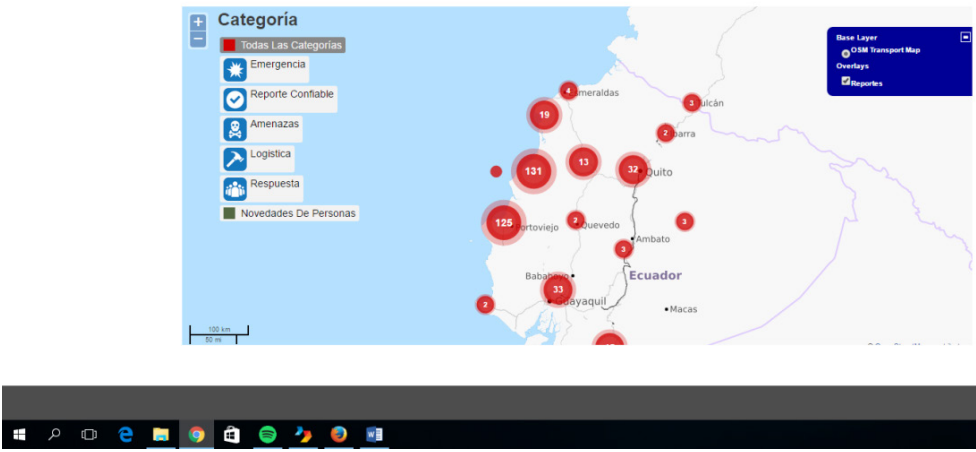

Imagen 2: Captura de pantalla de ayudaecuador.ec en donde se alberga el mapa de reportes de Open Street Maps.

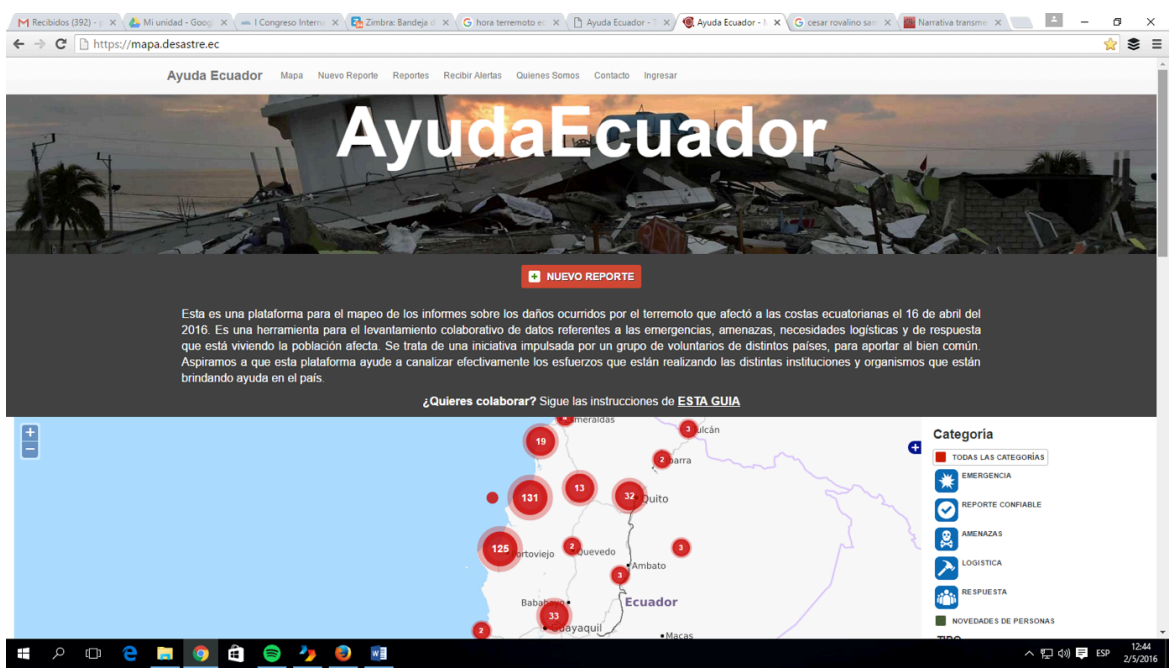

Imagen 3: Captura de pantalla de mapa.desastres.ec, elaborado con Ushaidi, en donde se alberga también el mapa de reportes de 0pen Street Maps. 
Este es uno de los elementos cohesionadores de esta comunidad, además del afán de ayudar humanitariamente, desde su experiencia y conocimiento, con el uso, desarrollo y la difusión de esta plataforma de uso libre y sus herramientas.

El nexo de esta comunidad, como lo dicen Bateman y Lyon (2002)"... The virtual community does not include identification with place, but it does require common ties and social interaction" (375), radica en la forma en que establece nexos y no en el espacio. Los lazos comunes y la interacción son vitales para estos cartografistas.

Two durable results of great significance emerge from the huge body of research that has been produced in recent years. First, studies of the origin and functions of online groups demonstrate the remarkable power of the medium to enable new forms of sociability. Second, studies that enquire into the motives for joining and contributing to these groups demonstrate consistently that online participation offers unique opportunities for actively and interactively pursuing identity-related projects that used to be impossible, and even inconceivable. (Feenberg y Bakardjieva. 2004. 40)
Definir una comunidad y vincularla estrechamente con el espacio es algo que se ha discutido a lo largo de los años, acerca de cómo es una verdadera comunidad, y en el entorno virtual, las redes son esenciales para la existencia de comunidades. El espacio virtual no es solo la plataforma que usan los miembros de la comunidad, no es solo el sitio geográfico o deslocalizado, también es el objeto o sujeto que se quiere modificar y transformar. En este caso, el espacio de transformación de la comunidad es la información generada por Open Street Maps, que permite este trabajo, a diferencia del Google Maps, en donde se puede incorporar información pero no a tal detalle ni en forma de capas.

Communities still exist most readily, most naturally, and most often when people identify with place-the neighborhood, the school, the church, ort the workplace-and personal, face-toface interactions are still important within the boundaries of a geographic area. (Bateman y Lyon. 2002. 388)

La identificación de los espacios a "mapear" son el cohesionador de esta comunidad y los encuentros presenciales, o mapatones son los más productivos, ya que se centran no en conocerse, sino en generar más voluntarios que puedan ingresar información válida so- 
bre el desastre: ubicación de casas, vías, población, escuelas, etc.

No existe una autoridad, pero sí unos guías más expertos que lideran los procesos colaborativos. Así, esta comunidad virtual, como define Sandy Stone (Jones. 2003), es un espacio social en el que el cara a cara se ha transformado a partir de un contacto virtual, marcado por y prácticas informáticas comunes de gente que se unió en un nodo desde sus espacios remotos, con una finalidad común, en donde el espacio se construye a partir de creencias, compromisos y prácticas comunes.

Más bien el espacio del ciberespacio se predica en el conocimiento y la información, en las creencias y prácticas comunes de una sociedad abstraída del espacio físico. Parte de este cono- cimiento e información, sin embargo, reside simplemente en saber cómo navegar por el ciberespacio. Pero el elemento importante en las relaciones sociales ciberespaciales es el hecho de que la información es compartida. Y no es que sea compartida en el sentido de la transmisión de información que amarra las comunidades al ciberespacio. Aquello que lo solidifica es el carácter ritual de la información compartida. (Jones. 2003: 36)

Los productos transmedia realizados se orientan a la formación y enlistamiento de voluntarios digitales, pero también de sistematización para consumo interno, que, a su vez fueron usados por los medios y cibermedios, como ejemplo de la labor hecha, una actividad más desde la sociedad civil. 


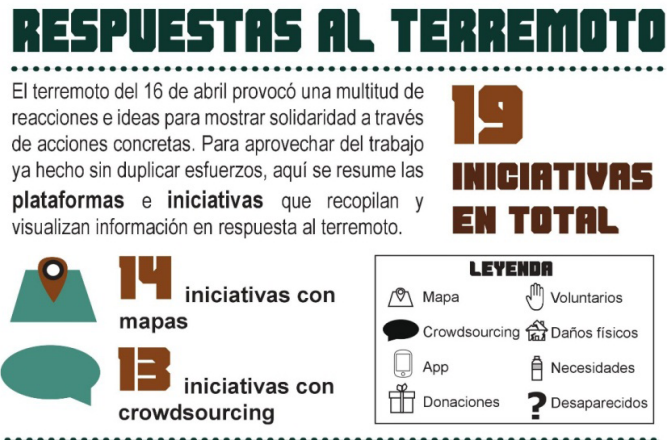

\begin{tabular}{|c|c|c|}
\hline HOMBRE & DEFHRPFHIX & |HARAHTERISTIFAS \\
\hline $\begin{array}{l}\text { Mapeo de Emergencia } \\
\text { Terremoto Ecuador }\end{array}$ & $\begin{array}{l}\text { Plataforma con referencias de centros de acopio, sitios con } \\
\text { necesidad, refugios, etc. en Ecuador }\end{array}$ & $\therefore \bigcirc$ 迥 \\
\hline Terremoto Ecuador & $\begin{array}{l}\text { Plataforma para georeferenciar la ayuda y los } \\
\text { requerimientos en las zonas afectadas. }\end{array}$ & $\square$ \\
\hline Unidos Ecuador & $\begin{array}{l}\text { Plataforma para brindar información sobre centros de } \\
\text { acopio (y que donar) en Ecuador }\end{array}$ & \\
\hline Ayuda Ecuador & $\begin{array}{l}\text { Mapeo de los informes sobre los daños ocurridos por el } \\
\text { terremoto }\end{array}$ & 的 \\
\hline DiviDamos & Hierramienta para gestionar las donaciones por el terremoto & $\theta$ \\
\hline $\begin{array}{l}\text { Humanitarian OSM } \\
\text { (\#Mapping Ecuador) }\end{array}$ & Crear un mapa base de pre y pos terremoto & 然象 \\
\hline Google Crisis Map & $\begin{array}{l}\text { Detallar las situaciones de la carretera; indican los centros } \\
\text { de donaciones, y las zonas que son seguras y las } \\
\text { peligrosas }\end{array}$ & 尚 \\
\hline YoVeoveo & Reportar sobre cualquier incidencia & - ब道 \\
\hline Mapillary & Captar y compartir fotos a nivel de calle & D知 \\
\hline OSM Tracker & $\begin{array}{l}\text { Una aplicación offline para recolectar puntos de interés } \\
\text { para luego anadir a mapas de OpenStroetMap }\end{array}$ & (1) 命 \\
\hline Actuemos Ecuador & $\begin{array}{l}\text { Gestionar el proceso de reconstrucción a desarrollarse } \\
\text { luego de atender las situaciones más urgentes }\end{array}$ & (in) \\
\hline Tomnod & Identificar daños físicos en las áreas afectadas & 峝 \\
\hline No Están Solos & $\begin{array}{l}\text { Recopilar las iniciativas que surgen para apoyar a las zonas } \\
\text { afectadas }\end{array}$ & 吕绝会 \\
\hline Residuos Ecuador & $\begin{array}{l}\text { Iniciativa ciudadana enfocada en la Gestión de Residuos } \\
\text { Sólidos y Liquidos, con propuestas técnicas para afrontar la } \\
\text { emergencia del terremoto en Ecuador. }\end{array}$ & 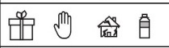 \\
\hline $\begin{array}{l}\text { DigitalGlobe } \\
\text { Developers }\end{array}$ & $\begin{array}{l}\text { Controlar la cartografia pre evento, todas las imágenes son } \\
\text { ortorectificadas 1:12000 }\end{array}$ & 要 䧻 \\
\hline Disastercharter & $\begin{array}{l}\text { Proveer imágenes satelitales en tiempo real de la zona de } \\
\text { desastre que obviamente sirven para todo, inclusive } \\
\text { detectar el nivel de dano. }\end{array}$ & 8 \\
\hline $\begin{array}{l}\text { Buscador Integrado de } \\
\text { Personas }\end{array}$ & $\begin{array}{l}\text { Aplicar principios de análisis de redes sociales, linked data, } \\
\text { open data e inteligencia colectiva para ayudar a la gestion } \\
\text { de los datos de los desaparecidos en el terremoto }\end{array}$ & \\
\hline People Locator & $\begin{array}{l}\text { Reportar personas desaparecidas utizando nombre y } \\
\text { apellidos }\end{array}$ & \\
\hline DondeAyudoEC & $\begin{array}{l}\text { Una plataforma para que representantes on los Centros de } \\
\text { Acopio puedan comunicar dónde se encuentran y quê } \\
\text { necesitan }\end{array}$ & ra \\
\hline
\end{tabular}

Imagen 4: Infografía realizada por Rachel Mulbry <rachelmulbry@gmail.com 


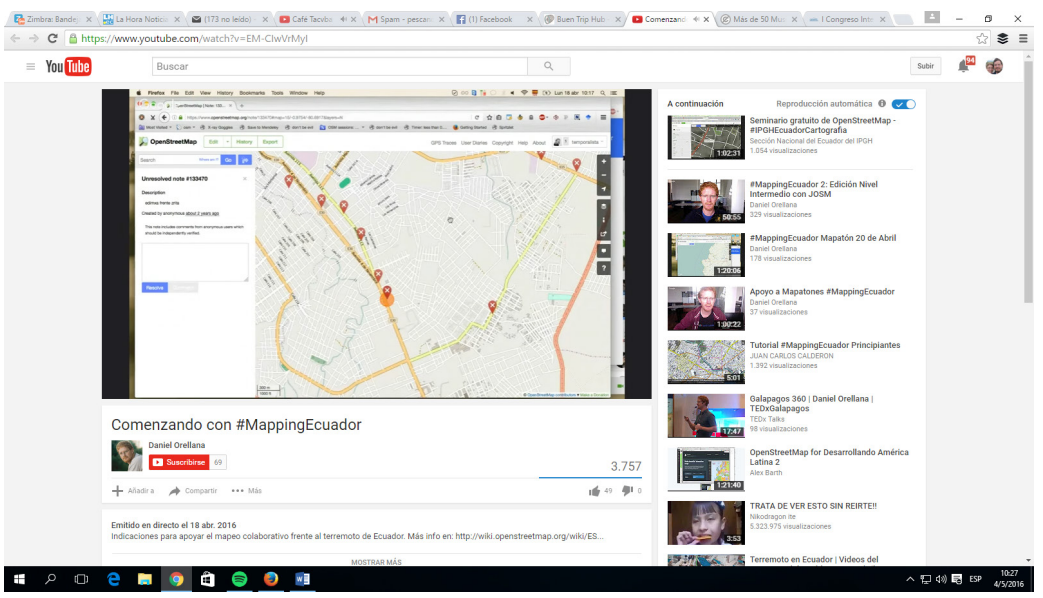

Imagen 5: Captura del video realizado por @temporalista (Daniel Orellana). Tomado de https://www.youtube. com/watch?v=EM-ClwVrMyl

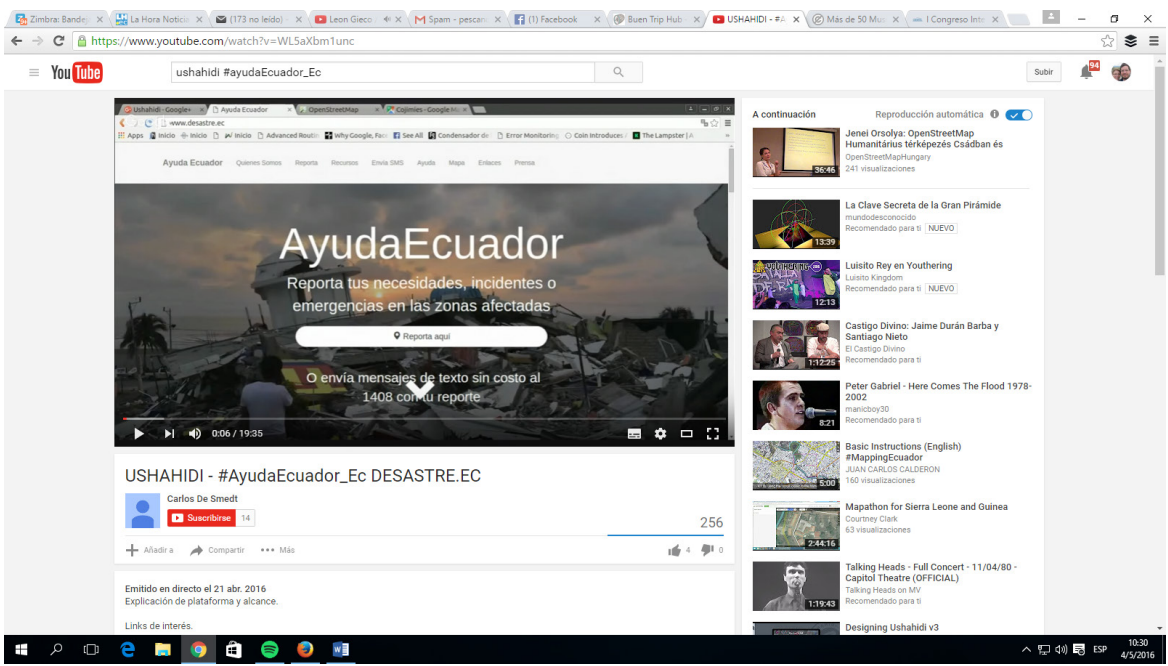

Imagen 6: Captura de pantalla del vídeo realizado por Carlos De Smedt. Tomado de: https://www.youtube. com/watch?v=WL5aXbm1unc 
Los tutoriales y la creación de comunidades virtuales de ayuda son temas que el periodismo transmedia colaborativo debe tomar en cuenta para generar contenidos contextualizados, con expertos que dejan de ser fuentes y se convierten en parte de los equipos de producción. De esta manera se genera un periodismo colaborativo y un verdadero ejercicio de inteligencias conectadas.

\section{CONCLUSIONES}

\section{LA COLABORACIÓN ENTRE COMUNIDADES Y CON EL PERIODISMO}

1. El periodismo ha cambiado. La tecnología y la organización social han modificado el trabajo del periodista, que deja de ser minero de fuentes para pasar a ser generador de comunidades.

2. El periodismo debe incluir a las comunidades digitales y tiene que ser parte de ellas, para generar mejores contenidos, con la participación de expertos en cada uno de sus ámbitos, que no dejan de ser fuentes pero a la vez se convierten en colaboradores creativos del contenido.

3. Las comunidades de profesionales, de expertos y de voluntarios, son espacios de inteligencias conectadas, con las cuales el periodismo está desconectado. Por lo tanto, en el periodismo digital aún no hay inteligencia colectiva, porque no se trabaja entre y con comunidades digitales. Estas son vistas como sujetos para ser des- critos en los medios y no como sujetos activos dentro de la generación y difusión de información.

4. Incluir a las comunidades colaborativas como elementos integrales en la generación de información es primordial en momentos de convulsión social, como en el caso del terremoto del pasado 16 de abril de 2016

5. La mutación del periodismo tradicional en digital no está en la tecnología por sí misma, sino en cómo se la usa para generar mayor reflexión, comprensión y difusión de un hecho.

6. El transmedia promueve la participación y la generación de conocimientos. Con la inclusión de equipos multidisciplinarios en la creación de contenidos, el periodismo digital es más profundo, más comprometido y se vuelve inmersivo.

7. El periodismo digital y las comunidades digitales trabajan con "softwa- 
re" cultural, material y herramientas comunes entre ellos, que lamentablemente aún no es asumido como cultural por los medios.

8. Desde la concepción cibercultural, el periodismo digital debe y tiene que ser activista con el "software" cultural, con el conocimiento abierto, con la inclusión de actores en la generación de contenidos. Las salas de redacción tienen que ser virtuales e incluir a las comunidades de desarrollo tecnológico, a los "geeks", a los expertos.

9. El MedialabUIO propone la creación de un espacio en común para informar, desarrollar la herramienta y crear contenido para todos los usuarios, desde una horizontalidad colaborativa con una motivación en común: generar insumos y datos útiles para mitigar y prevenir desastres. Ese es el fin último del trabajo humano con tecnología. 


\section{BIBLIOGRAFÍA}

BATEMAN DRISKELL, R. \& LYON, L. (2002) "Are Virtual Communities True Communities? Examining the Environments and Elements of Community" .City \& Community, Vol 1 (4): 373-390.

BAYM, N. (1998) "La emergencia de comunidad virtual". A Jones, S.G. (edt.) (1998) Cibersociedad 2.0. Barcelona: Editorial UOC, 2003.

FEENBERG, A. \& BAKADIJEVA, M. (2004) "Virtual community: no 'Killer implication"'. New Media \& Society, Vol. 6 (1): 37-43.

GALÁN, José Ignacio (2014). "La transmedialidad, una nueva gramática para el sujeto complejo", en Portal de la Comunicación, recuperado el 10 de julio de 2015 de http:// portalcomunicacion.com/lecciones_det.asp?id=71.

JENKINS, Henry (2008). Convergence culture. Barcelona: Paidós.

JENKINS, Henry (2014). "Transmedia 202", en Henryjenkings.com, recuperado el 10 de julio de 2015, de http://henryjenkins.org/2014/09/ transmedia-202-reflexiones-adicionales.html

JONES, S. "Información, Internet y comunidad: apuntes para una comprensión de la comunidad en la era de la información". A Jones,
S.G. (edt.) (1998) Cibersociedad 2.0. Barcelona: Editorial UOC, 2003.

IRIGARAY, F. y LOVATO, A (2015). Producciones transmedia de no ficción. Análisis, experiencias y tecnologías. Rosario: UNR Editora. Editorial de la Universidad Nacional de Rosario.

MANOVICH, Lev (2006). El lenguaje de los nuevos medios. Buenos Aires: Paidós.

MANOVICH, Lev. (2012). El software toma el mando, recuperado el 10 de abril de 2015, de https://www. academia.edu/7425153/2014_ El_software_toma_el_mando_ traducci\%C3\%B3n_a_Lev_Manovich_

MARTÍN SERRANO, Manuel (2008). La mediación social. Madrid, España: Akal.

MARTÍN-BARBERO, Jesús (1998) (v edición). De los medios a las mediaciones. Bogotá: Convenio Andrés Bello.

MURRAY, Janeth (1999). Hamlet en la holocubierta. El futuro de la narrativa en el ciberespacio. Bacelona: Paidós.

Pavlik, John (2008). Media in the Digital Age. New York: Columbia Press University. 
Piscitelli, Alejandro (2002). Ciberculturas 2.0. En la era de las máquinas inteligentes. Buenos Aires: Paidós.

Porto, Denis, y Flores, Jesús (2012). Periodismo transmedia. Madrid: Editorial Fragua.

RENÓ, D., CAMPALANS, C., RUIZ, S., GOSCIOLA V. (2013). Periodismo Transmedia: miradas múltiples. Bogotá: Universidad del Rosario.

RENÓ, D. y RENÓ, L. (2013). "Narrativa Transmedia y mapas interactivos: periodismo contemporánea", en Revista Razón y Palabra NÚMERO 83 JUNIO - AGOSTO 2013. Recuperado el 2/05/2016 de http://
www.razonypalabra.org.mx/N/ N83/N83/40_RenoReno_V83.pdf

Scolari, Carlos (2004). Hacer clic. Hacia una sociosemiótica de las interacciones digitales. Barcelona: Gedisa.

Scolari, Carlos (2008). Hipermediaciones. Elementos para una Teoría de la Comunicación Digital Interactiva. Barcelona: Gedisa.

\section{Recursos web}

http://wiki.openstreetmap.org/wiki/ ES:2016_Ecuador_earthquake\#Eventos_y_Mapatones 
